9. Цыбрий А.В., Цыбрий В.В. Проблемы периодизации и хронологии раннего неолита Нижнего Дона, Восточного и Северо-Восточного Приазовья // Археологическое изучение Центральной России. Липецк, 2006. С. 95-97.

10. Цыбрий А.В., Цыбрий В.В., Зайцева Г.И., Кулькова М.А., Долбунова Е.В., Мазуркевич А.Н. Радиоуглеродная хронология неолита Нижнего Дона и Северо-Восточного Приазовья // Радиоуглеродная хронология эпохи неолита Восточной Европы VII-III тысячелетия до н.э. / сост. Г.И. Зайцева, О.В. Лозовская, А.А. Выборнов, А.Н. Мазуркевич. Смоленск, 2016. C. 213-243.

11. Долуханов П.М., Шукуров А., Гроненборн Д., Зайцева Г.И., Тимофеев В.И., Соколов Д.Д. К статистике радиоуглеродной хронологии раннего неолита юга Восточной Европы // Археологические записки. Вып. 3. Ростов-на-Дону, 2003. С. 76-82.

12. Мазуркевич А.Н., Долбунова Е.В., Кулькова М.А. Керамические традиции в раннем неолите Восточной Европы // Российский археологический ежегодник. 2013. № 3. С. 27-109.

13. Синюк А.Т. О формировании неолитических культур лесостепного Дона // Тезисы науч.-краевед. конф., посв. основателю Липецкого областного краевед. музея Трунову М.П. Липецк, 1995. С. 27-29.

14. Синюк А.Т. Проблемы хронологии неолита лесостепного Подонья // Проблемы хронологии и этнокультурных взаимодействий в неолите Евразии. СПб., 2004. С. 195-206.

15. Гапочка С.Н., Скоробогатов А.М., Сурков А.В. Развитие материальной культуры населения эпохи неолита Среднего Дона в свете современных исследований // Неолитические культуры Восточной Европы: хронология, палеоэкология, традиции: мат-лы междунар. науч. конф., посв. 75-летию В.П. Третьякова. СПб.: ИИМК РАН, 2015. С. 115-118.

16. Васильева И.Н. К вопросу о гончарных традициях неолитического населения Подонья // Известия СНЦ РАН. 2017. Т. 19, № 3 (2). С. 370-379.

17. Скоробогатов А.М., Смольянинов Р.В., Сурков А.В., Ойнонен М., Посснерт Г. Хронология неолитических памятников лесостепного Подонья // Радиоуглеродная хронология эпохи неолита Восточной Европы VII-III тысячелетия до н.э. / сост. Г.И. Зайцева, О.В. Лозовская, А.А. Выборнов, А.Н. Мазуркевич. Смоленск, 2016. С. 244-260.

18. Выборнов А.А., Кулькова М.А., Ойнонен М., Посснерт Г. Новые радиоуглеродные даты неолитических памятников Подонья // Известия СНЦ РАН. 2017. Т. 19, № 3 (2). С. 366-369.

19. Скоробогатов А.М., Яниш Е.Ю., Александровский А.Л. Неолитическая стоянка Черкасская-5 на Среднем Дону. Соотношение охоты и рыболовства по фаунистическим и археологическим данным // Стратегии жизнеобеспечения в каменном веке, прямые и косвенные свидетельства рыболовства и собирательства: материалы междунар. конф., посв. 50-летию В.М. Лозовского. СПб., 2018. С. 72-75.

20. Tsybrij A., Tsybrij V., Dolbunova E., Mazurkevich A., Kulkova M., Zaitseva G. Radiocarbon chronology of Neolithic in the Lower Don and North-eastern Azov Sea // Documenta Praehistorica. XLIV. Ljubljana, 2017. P. 204-222.

\title{
SOME SIMILARITY FEATURES IN THE NEOLITHIC LOWER AND MIDDLE DON
}

(C) 2018

Gapochka Sergey Nikolaevich, candidate of historical sciences, associate professor of Domestic History Department

Voronezh State Pedagogical University (Voronezh, Russian Federation)

Surkov Alexey Vladimirovich, candidate of historical sciences, archaeologist

Center for Security Archaeological Research (Voronezh, Russian Federation)

Abstract. The paper considers the influence of Rakushechny Yar settlement research on ideas about the Middle Don Neolithic. Traditionally, the Lower Don Region was considered as one of the centers of the Middle Don Neolithic culture. The paper contains a comparison of the stone and ceramic inventory of the Rakushechny Yar with the materials of the Middle Don Culture sites. There are common features: stone inventory lamellar with a small number of geometric forms, acute vascularity, the use of pointed ornamentation, technological methods of vessel surface processing. At the same time, a large number of differences in the comparison of Early Neolithic materials of the Lower and Middle Don allow one to conclude that there is no genetic connection between the Middle Don and Rakushechny Yar cultures. In addition, the paper presents the study of the Cherkasskaya 5 site, its materials precede the Srednodonsk in chronological order and have many similarities with the finds from the lower layers of Rakushechny Yar settlement. Thus, the stone inventory of Cherkasskaya 5 is plate, geometric microliths are not found.

Keywords: Lower Don; Medium Don; settlement of Rakushechny Yar; Monastery I site; Cherkasskaya 5 site; Shchuchye II site; shell culture; mid-Don culture; absolute chronology; unreinforced ceramics; pendent ornamentation; acute vessels; conditions of occurrence; cultural layer; shell rock.

УДК 902.01

Статья поступила в редакцию 11.06.2018

\section{СТОЯНКА ЧЕРКАССКАЯ-5 И ЕЕ МЕСТО В РАННЕМ НЕОЛИТЕ СРЕДНЕГО ДОНА}

(C) 2018

Скоробогатов Андрей Михайлович, кандидат исторических наук, начальник археологического отдела ООО «Терра» (2. Воронеж, Российская Федеращии)

Аннотаџия. Статья вводит в научный оборот материалы стоянки Черкасская-5, расположенной на Среднем Дону в Павловском районе Воронежской области. Под двухметровой толщей озерно-аллювиальных от- 
ложений выявлено больше тысячи единиц находок: лепная керамика, изделия из камня и кости, остеология. При анализе материалов памятника выделяется керамический и кремневый комплекс ранненеолитического облика (7-6 тыс. до н.э.). Полученные радиоуглеродные даты, данные технико-технологического анализа и особенности орнаментации керамики, типология каменного и костяного инвентаря позволяют конкретно отметить один из возможных путей неолитизации Среднего Подонья, в котором ведущая роль принадлежит степному компоненту. Проведенный палеозоологический анализ показал, что в остеологической коллекции доминируют кости птиц (64,4\% от всех костей), присутствуют млекопитающие $(21,8 \%)$, рыбы $(9,7 \%)$, черепаха болотная $(4,1 \%)$. Среди млекопитающих определены домашние виды (собака, лошадь, свинья, овца). Однако наличие в слое керамики позднего неолита и энеолита (среднедонская, днепро-донецкая, нижнедонская и среднестоговская культуры) оставляют открытым вопрос о принадлежности домашних видов животных к раннему неолиту. Материал памятника позволяет характеризовать данное место как серию сезонных кратковременных специализированных площадок, предназначенных для ведения сетевого рыболовства, охоты на водоплавающую птицу, отлова черепах и сбора моллюсков, а также для обработки получаемой продукции рыболовства и охоты в эпоху неолита.

Ключевые слова: Средний Дон; река Битюг; Воронежская область; лесостепь; раскопки; стоянка; стратиграфия; керамика; изделия из камня и кости; радиоуглеродные даты; ранний неолит; степная традиция; накольчато-прочерченная орнаментация; орловская культура; охота; рыболовство; грузила; собирательство; домашние животные.

Памятник расположен в срезе левого берега р. Битюг, в 1,8 км от места его впадения в р. Дон в Павловском районе Воронежской области (рис. 1: 1). Выявлен экспедицией ВГПУ во время раскопок стоянки Черкасская-3 в 2012 г., когда со дна сильно обмелевшей к тому моменту реки был собран подъемный материал, а в обнажениях берега обнаружен выход ракушечника. В 2014 г. для выяснения локализации культурного слоя было осуществлено две зачистки протяженностью по 3 м на расстоянии 20 м друг от друга. В зачистке № 1 выявлено 503 находки, в зачистке № 2 - всего 26. В 2015 г. возле зачистки № 1 был заложен раскоп площадью около $20 \mathrm{M}^{2}$, из которого происходило 1194 находки [1].

По мнению А.Л. Александровского, обследовавшего стратиграфию в зачистке № 2, памятник расположен на участке с озерно-аллювиальной толщей отложений с высоким содержанием органического вещества (старичный аллювий, сапропель, торф, озерные глины). В основании зачистки находились маломощные озерные отложения (сапропель), выше залегают пески, свидетельствующие об активизации русловых процессов. Выше лежат аллювиальные отложения, предположительно старичные, с высоким содержанием органического вещества. В верхней их части имеются следы зарастания старичного понижения и периодического накопления торфа. Самая верхняя часть отложений, в связи с дальнейшим обсыханием участка, подвергается воздействию процессов почвообразования. Формируется черноземнолуговая почва [2, с. 72].

Стратиграфия отложений (описание дается по профилю восточного борта раскопа, см. рис. 1: 2):

1) $0-10 \mathrm{~cm}-$ дерн;

2) 10-60 см - луговой чернозем (вмещал в себя часть переотложенного грунта, образованного при чистке русла реки в советское время);

3) 60-130 см - старичный аллювий А;

4) 130-180 см - старичный аллювий Б;

5) 180-215 см - светлый песок с обильным содержанием раковин;

6) 215-220 см - светлый песок без раковин;

7) 220-230 - илистая прослойка с содержанием фрагментов древесины и раковины;
8) 230-255 см - светлый песок с содержанием раковин. Встречены археологические находки (фрагменты керамики, находки из камня и кости);

9) 255-260 см - серый песок с содержанием раковин. Встречены археологические находки (фрагменты керамики, находки из камня и кости);

10) с 260 см - материк (сапропель). Археологические находки отсутствовали (кроме нескольких единиц крупных меловых изделий, опустившихся из вышележащего слоя).

После снятия слоя балласта штыковыми лопатами расчистка культурного слоя велась садовыми совками и ножами единым уровнем по всей площади раскопа и зачисток. Фиксация находок велась по квадратам. Каждой находке присваивался индивидуальный номер, отмечались ее координаты в сантиметрах - горизонтальные от единой условной точки, которой явился северо-восточный угол раскопа, и вертикальные, от репера.

Ямы, постройки или столбовые ямки в пределах раскопа и зачисток выявлены не были.

\section{Особенности поглубинного}

распространения находок.

Археологический материал залегал в двух литологических слоях: в слое светлого песка с содержанием раковин (слой 8) и в слое серого песка с содержанием раковин (слой 9), подстилаемых материковым сапропелем. При анализе поглубинного распределения материала наиболее информативной оказались данные керамических комплексов. Так, оказалось, что керамика первой группы (с примесью раковины в тесте) залегает в верхней части отложений (слой 8) совместно с керамикой 2-3 групп (запесоченная керамика), а в нижней части (слой 9) практически не встречена керамика 2-3 групп при доминировании керамики группы 1. Находки из кремня располагаются достаточно компактно в слое 8, при незначительном «опускании» находок с нижележащий слой 9, для изделий из мела характерно тяготение к слою 9. Однако делать выводы о наличии двух разновременных стратиграфических слоях на исследованном участке памятника пока преждевременно. Необходимо учитывать рыхлую структуру песчаных слоев 8-9. Скорее всего, этим объясняется «проседание» более тяжелых, по сравнению с кремнем, изделий из мела. Также необходимо отметить значительное количественное преобладание керамики группы 1 над керамикой других групп. 

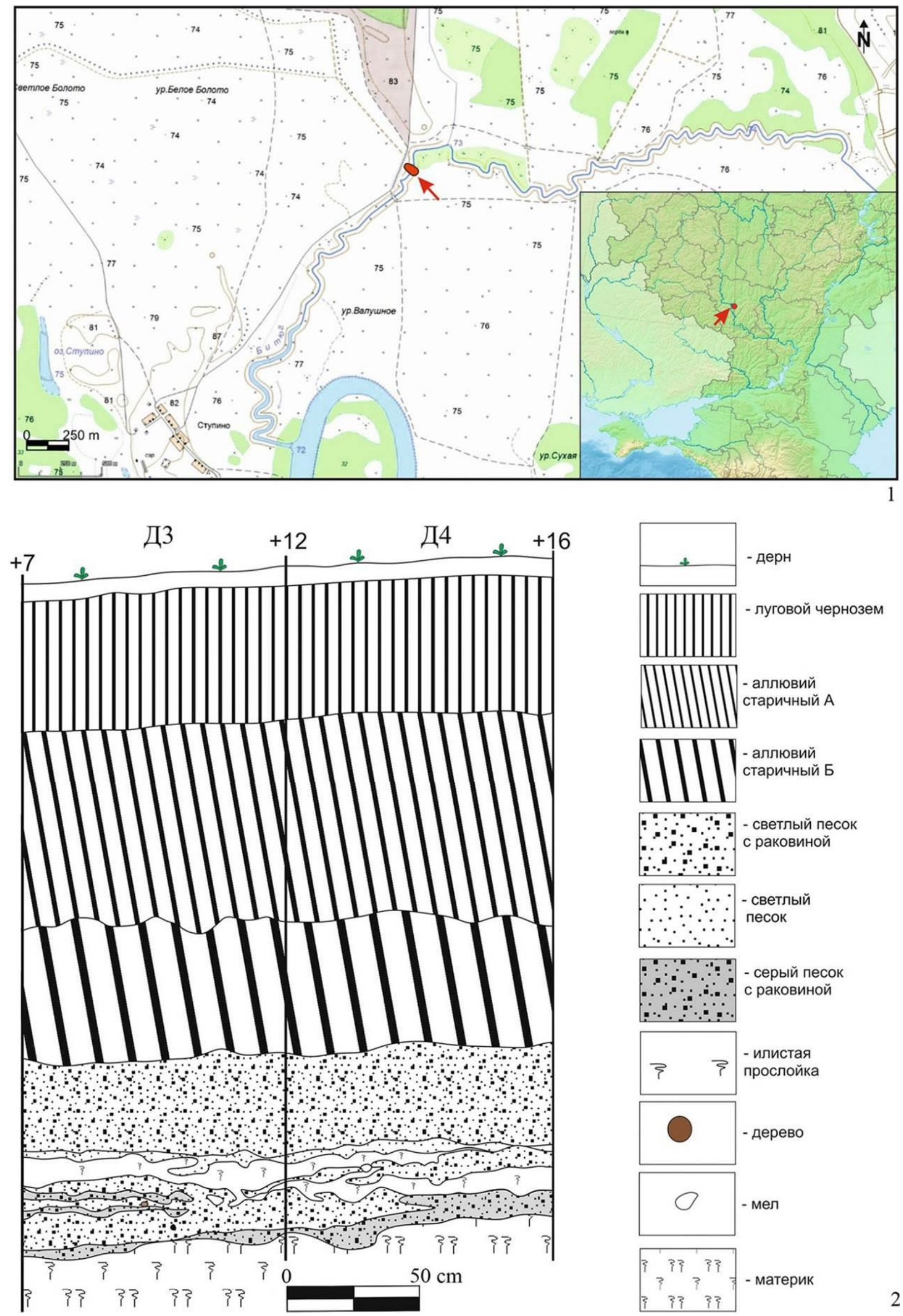

Рисунок 1 - Стоянка Черкасская-5.

1 - карта-схема расположения памятника; 2 - стратиграфия и условные обозначения

Планиграфическое распределение находок в раскопе не показывает какой-либо четкой картины их распространения как по общему залеганию находок, так и при делении их по категориям. В целом это можно объяснить малой исследованной площадью и характером самого памятника. 
Находки из культурного слоя

С раскопа и зачисток происходит 1723 находки, из них кость - 880 (51,1\%), камень - 508 (29,5\%), керамика - 294 (17,1\%), фрагменты угля, дерева, охра 40 единиц $(2,3 \%)$.

\section{Кость}

Находки из кости выявлены в количестве 880 единиц. Е.Ю. Яниш были изучены 689 костей животных (из них 150 - млекопитающие, 179 - птицы, 143 - рыбы и 162 - рептилии).

Кости птиц доминируют в остеологической коллекции, и составляют $64,4 \%$ от всех костей, млекопитающие - $21,8 \%$, рыбы - 9,7\%, еще $4,1 \%$ принадлежали остаткам черепахи болотной (Emys orbicularis).

Домашним животным принадлежит половина $(50,0 \%)$ от всех определенных до вида костей. Так, в коллекции присутствуют кости лошади домашней (Equus caballus), свиньи домашней, собаки домашней (Canis familiaris), а также овцы (Ovis aries) и, возможно, козы домашней (Capra hircus). Выборка определимых костей млекопитающих невелика, тем не менее можно отметить, что значительную часть от этого количества составляют кости лошади и собаки. Из диких млекопитающих выявлены кости лося (Alces alces) и кабана (Sus scrofa).

Из определенных до вида костей птиц 45 экземпляров принадлежат уткам, в первую очередь - кряквам (Anas platyrhynchos). Среди всех костей рыб доминирует щука (Esox lucius) - 62,7\%, на втором месте сом (Silurus glanis) - 15,0\%, на третьем месте сазан (Cyprinus carpio) - 10,4\%, в одном случае найдена чешуя окуня (Perca fluviatilis) [2, с. 73].

Однако судить о времени появления домашних животных на Среднем Дону по имеющимся источникам еще рано до проведения абсолютного датирования непосредственно самих остеологических материалов. Напомним, что на расположенной рядом многослойной стоянке Черкасская (раскопки А.Т. Сиюнка 1979 и 1981 гг.) были определены кости домашних видов: собака, свинья, корова, мелкий рогатый скот, при том что видовой состав почти не изменялся с глубиной [3, с. 87].

Изделия из кости немногочисленны, представлены наконечниками и остриями, их обломками (рис. 2: 1-3, 5), кочедыком (рис. 2: 7), возможно жерлицей (рис. 2: 4) остальные обработанные находки из кости представлены в обломках, и об их первоначальных размерах и функциях судить трудно (рис. 2: $6,8)$. Имеется обломок изделия из рога (рис. 2: 9). Привлекают к себе внимание фрагменты панцирей черепах с нанесенными горизонтальными и вертикальными насечками на внутренней стороне, вероятно, возникшими при разделке.

\section{Камень}

Из 508 находок 143 выполнены из кремня, 11 из кварцита, 76 из песчаника, 24 из сланца, остальные породы единичны (кварц, гранит, мергель, диабаз). К этой категории нами отнесены находки из мела (231 ед.), однако при дальнейшей статистической обработке мы их не учитывали, т.к. они представлены грузилами (с явными признаками обработки) или гальками (без видимых признаков обработки).
Орудия из камня изготавливались в основном из кремня (черный меловой, реже - валунный цветной, всего 143 ед.). Первичная обработка кремня проводилась за пределами исследованной части стоянки, вторичная - на ее территории, о чем свидетельствует присутствие нуклеусов, нуклевидных обломков и сколов подправки нуклеусов (рис. 3: 8-11), отбойников (рис. 4: 4-7, 9), чешуек. Нуклеусы небольших размеров (до 5 см), пирамидальные (3 экз.), плоские (2 экз.), уплощенные клиновидные (1 экз.) и призматические (1 экз.), прямо- и косо-площадочные, с негативами от пластинчатых заготовок (рис. 3: 1-7). Кремневая индустрия носит ярко выраженный пластинчатый облик. Использовавшиеся пластинчатые заготовки шириной более 1,2 см редки, наиболее характерны пластинки и микропластинки и их сечения, в основном с ретушью, реже - без ретуши (рис. 3 : $12-42,44,47)$. К геометрически микролитам можно отнести две низкие трапеции (рис. 3: 30, 31), изделия типа параллелограмма (рис. 3: 29) и типа сегмента с подтеской с брюшка (рис. 3: 34). Часть пластин характеризуются наличием ретуши с брюшка (рис. 3: 15-18, 20, 26, 33, 37). Вероятно, функцию вкладышей выполняли пластины и их сечения, т.к. значительная их часть имеет обработку с брюшка, а некоторым придавалась трапециевидная форма без обработки торцевых граней. Присутствуют скошенное острие (рис. 3: 25) и пластина с притупленным ретушью краем (рис. 3: 28). Орудийный набор включает ножи (4 экз., рис. 3: 39-42), резцы (4 экз., рис. 3: 45-47), скребки (3 экз., рис. 3: 48-50), по одному экземпляру - скобель, перфоратор (рис. 3: 44), проколка. Имеется обломок бифаса (рис. 3: 43). Особенностью орудийного комплекса следует считать малочисленность кварцита - отметим лишь одно сечение пластины без ретуши (рис. 3: 38). Также обнаружены тесла (6) и их обломки (рис. 4: 1-3). Значительный процент изделий со вторичной обработкой занимают абразивы, различные фрагментированные плитки с заполированной поверхностью, отбойники (раздел таблицы 1 «Прочее», рис. 4: 8). Данные о находках из камня приведены в таблице 1 .

Интересны находки из мела (231 экземпляр), часть из которых несет следы обработки и использования, и их можно отнести к категории грузил (рис. 5). Это изделия с углублениями для фиксации (U- и V-образной в сечении формы), расположенные минимум на двух гранях изделия, как правило - на противоположных либо опоясывающих изделие целиком в средней части. По размерам изделия встречены от миниатюрных, весом от 25 г, до крупных, весом свыше 500 г, при максимуме в 1146 г. На одном изделии сохранились фрагменты органической обмотки (рис. 5: 3). На некоторых меловых гальках иногда встречены пропилы, располагающиеся лишь на одной из сторон, иногда на них наносились прочерки и насечки, не образуя какого-либо четкого узора (рис. 5: 8, 10, 11). Не исключено, что часть меловых галек (уплощенные подпрямоугольные или округлые) также использовалась как грузила, однако желобки для фиксации на них не делались. Сейчас выходы мела имеются в обнажениях коренного правого берега Битюга в 2 км от Черкасских стоянок. 

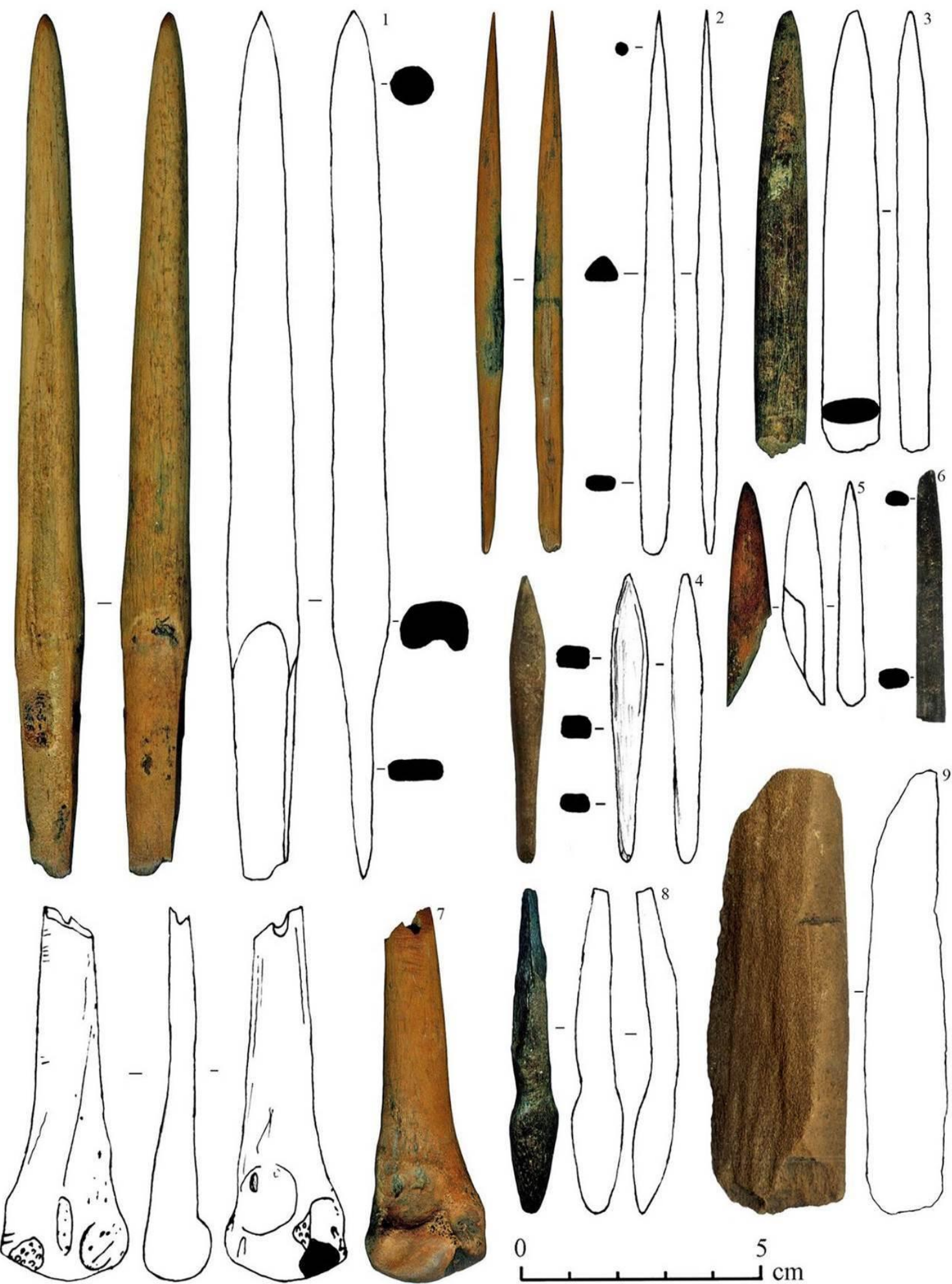

Рисунок 2 - Стоянка Черкасская-5. Изделия из кости (1-8) и рога (9)

Керамика

Керамика из раскопа делится на четыре группы (всего 294 фрагмента). Керамика первого типа самая многочисленная (215 фрагментов приблизительно от 35-40 сосудов). Характеризуется плотным тестом с обязательной примесью раковины. Поверхности заглажены, иногда до лощения, без расчесов. Сосуды прямостенные, со слегка стянутым верхом, баночной формы. Реконструируемый диаметр сосудов от 30 до 14 см (в среднем - 24-18 см). Срезы венчиков различной формы - в основном приостренные, реже округлые либо уплощенные. Обнаруженные донца (всего два экз.) принадлежали округлодонным сосу- дам, одно со сквозным отверстием, без орнамента (рис. 6: 4, 7). Встречен крупный фрагмент «ладьевидного» сосуда (миска?) с прочерчено-накольчатым орнаментом (рис. 6: 3). Лишь один сосуд был с ямочным пояском по венчику (рис. 6: 10). Шесть сосудов были с гофрированным либо орнаментированным срезом. Орнамент на керамике покрывал верхнюю и реже - среднюю часть посуды. Орнаментальные композиции представлены как горизонтальными рядами (рис. 6: 2, 4, 8, 9; рис. 7: 2, 4-7, 12-14), так и геометрическими мотивами с треугольными или прямоугольными фигурами, зигзагом, сеткой (рис. 6: $1,3,5,6,10,11$; рис. 7: 1, 3, 8-11). Орнамент нано- 
Скоробогатов А.М.

сился в технике накалывания и прочерчивания, спаренным штампом типа накола (рис. 6: 1, 2, 5, 6, 10; рис. 7: 4, 6, 12, 13), подтреугольным (рис. 6: 4; рис. 7: $2,5,8)$ и «подкововидным» наколом (рис. 6: 8; рис. 7: $3,7,14)$, штампом с рубчатым основанием - возможно, это позвонки рыб (рис. 7: 10), плоским узким штампом (рис. 6: 9; рис. 7: 1, 6). Изредка встречены неглубокие ямчатые вдавления, оттиски панциря улитки (рис. 7: 9), прочерки (рис. 6: 11; рис. 7: 11), иногда в сочетании с наколом (рис. 6: 3). Значительная часть керамики этой группы не имела орнамента (137 фрагментов). Керамику данной группы дополняют фрагменты, поднятые со дна реки во время обнаружения памятника в 2012 г. (рис. 8, 9). Некоторые из них принадлежали сосудам, фрагменты которых позже были расчищены в культурном слое (рис. 7: 10; рис. 9: 5).

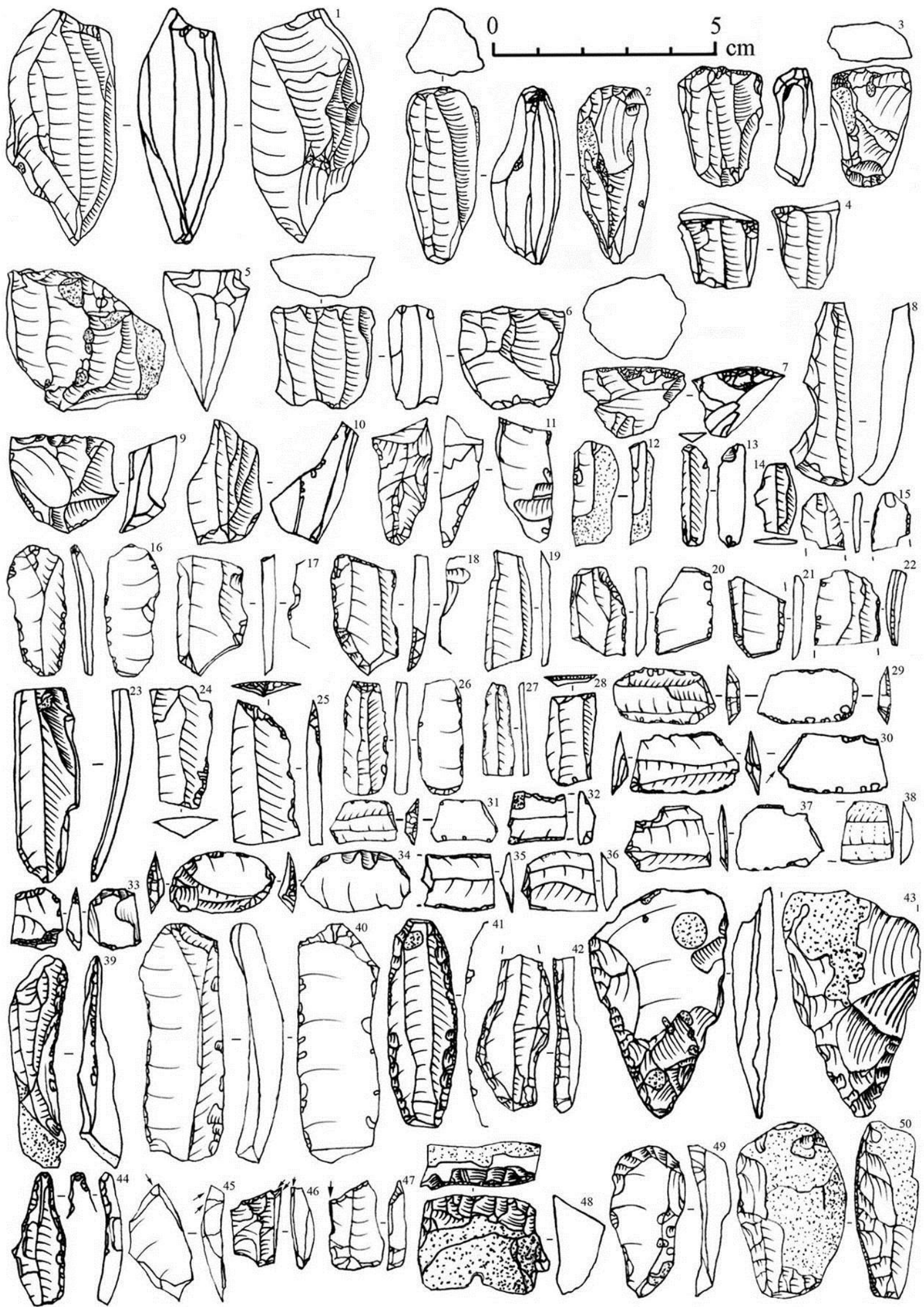

Рисунок 3 - Стоянка Черкасская-5. Изделия из кремня (1-37, 39-50) и кварцита (38) 
Керамика 2-3 групп (82 фрагмента от 15-20 сосудов) схожа между собой, но значительно отличается от керамического материала первой группы. Керамика группы 2 характеризуется запесоченным тестом без иных видимых отощителей. Орнамент накольчатый, накольчато-гребенчатый, накольчатоямочный, встречены ямочные пояски по венчику. Отмечается прием ангобирования поверхностей. Внутренние поверхности иногда покрыты расчесами (рис. 10: 1-6, 8-10, 12, 17). Интересен развал сосуда, реконструированный графически. Профиль $\mathrm{S}$-видной формы, диаметр по венчику 18-20 см, срез веничка гофрирован. В верхней части украшен горизонтальными рядами крупного накола, по тулову - горизонтальными рядами ямчатых вдавлений, ниже которых расположены треугольные композиции, выполненные наколом (рис. 10: 1). Керамика третьей группы характеризуется примесью органики в запесоченном тесте, единообразием орнаментации: встречены спаренные наколы, прочерченные линии, оттиски панциря улитки (рис. 10: 11, 13-16, 19). Керамика второй группы типична для среднедонской неолитической культуры, третьей - для днепро-донецкой неолитической традиции (донецкая культура).

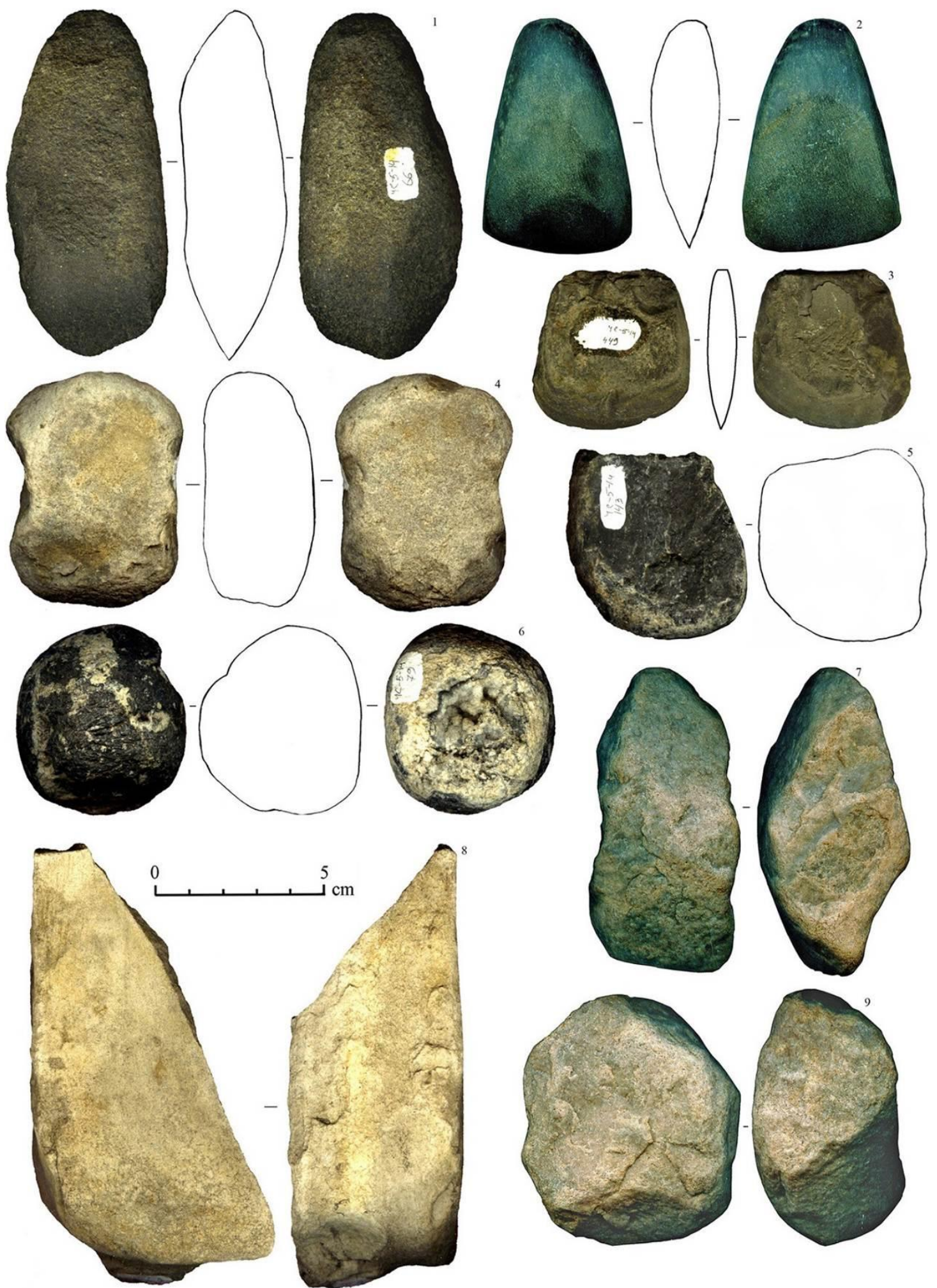

Рисунок 4 - Стоянка Черкасская-5. Орудия для деревообработки (1-3), отбойники $(4-7,9)$ и фрагмент полированной плиты $(8)$ 
Таблица 1 - Находки из камня из культурного слоя стоянки Черкасская-5. Работы 2014-2015 гг.

\begin{tabular}{|l|c|c|c|c|c|c|c|}
\hline \multirow{2}{*}{ Тип находки } & \multicolumn{2}{|c|}{ Кремень } & \multicolumn{2}{|c|}{ Песаник } & \multicolumn{2}{|c|}{ Прочее } & Всего \\
\cline { 2 - 7 } & $\begin{array}{c}\text { еди- } \\
\text { ницы }\end{array}$ & $\begin{array}{c}\text { про- } \\
\text { центы }\end{array}$ & $\begin{array}{c}\text { еди- } \\
\text { ницы }\end{array}$ & $\begin{array}{c}\text { про- } \\
\text { центы }\end{array}$ & $\begin{array}{c}\text { еди- } \\
\text { ницы }\end{array}$ & $\begin{array}{c}\text { про- } \\
\text { центы }\end{array}$ & $\begin{array}{c}\text { единицы/ } \\
\text { проценты }\end{array}$ \\
\hline Сырье: гальки, желваки и их обломки & $\mathbf{5}$ & $\mathbf{1 , 8 1 \%}$ & $\mathbf{7}$ & $\mathbf{2 , 5 3 \%}$ & $\mathbf{1 0}$ & $\mathbf{3 , 6 1 \%}$ & $\mathbf{2 2 / 7 , 9 5 \%}$ \\
\hline Изделия без вторичной обработки: & $\mathbf{1 1 0}$ & $\mathbf{3 9 , 7 1 \%}$ & $\mathbf{5 0}$ & $\mathbf{1 8 , 0 5 \%}$ & $\mathbf{3 2}$ & $\mathbf{1 1 , 5 5 \%}$ & $\mathbf{1 9 2 /} \%$ \\
\hline Нуклеусы & 7 & $2,53 \%$ & - & - & - & - & $7 / 2,53 \%$ \\
\hline Нуклевидные обломки & 11 & $3,97 \%$ & - & - & - & - & $11 / 3,97 \%$ \\
\hline Сколы подправки нуклеусов & 5 & $1,81 \%$ & - & - & - & - & $5 / 1,81 \%$ \\
\hline Пластины и их сечения & 13 & $4,69 \%$ & - & - & 1 & $0,36 \%$ & $14 / 5,05 \%$ \\
\hline Отщепы, сколы & 68 & $24,55 \%$ & 50 & $18,05 \%$ & 30 & $10,83 \%$ & $148 / 53,43 \%$ \\
\hline Чешуйки & 6 & $2,17 \%$ & - & - & 1 & $0,36 \%$ & $7 / 2,53 \%$ \\
\hline Изделия с вторичной обработкой: & $\mathbf{3 2}$ & $\mathbf{1 1 , 5 5 \%}$ & $\mathbf{1 9}$ & $\mathbf{6 , 8 6 \%}$ & $\mathbf{1 2}$ & $\mathbf{4 , 3 3 \%}$ & $\mathbf{6 3 / 2 2 , 7 4 \%}$ \\
\hline Пластины и их сечения с ретушью & 15 & $5,42 \%$ & - & - & - & - & $15 / 5,42 \%$ \\
\hline Скребки & 3 & $1,08 \%$ & - & - & - & - & $3 / 1,08 \%$ \\
\hline Скобели & 1 & $0,36 \%$ & - & - & - & - & $1 / 0,36 \%$ \\
\hline Перфораторы & 1 & $0,36 \%$ & - & - & - & - & $1 / 0,36 \%$ \\
\hline Ножи & 4 & $1,44 \%$ & - & - & - & - & $4 / 1,44 \%$ \\
\hline Геометрические микролиты & 4 & $1,44 \%$ & - & - & - & - & $4 / 1,44 \%$ \\
\hline Бифас & 1 & $0,36 \%$ & - & - & - & - & $1 / 0,36 \%$ \\
\hline Острия & 1 & $0,36 \%$ & - & - & - & - & $1 / 0,36 \%$ \\
\hline Резцы & 4 & $1,44 \%$ & - & - & - & - & $4 / 1,44 \%$ \\
\hline Тесла, топоры & - & - & - & - & 8 & $2,89 \%$ & $8 / 2,89 \%$ \\
\hline Прочее & - & - & 19 & $6,86 \%$ & 4 & $1,44 \%$ & $23 / 8,3 \%$ \\
\hline & $\mathbf{1 4 7}$ & $\mathbf{5 3 , 0 7 \%}$ & $\mathbf{7 6}$ & $\mathbf{2 7 , 4 4 \%}$ & $\mathbf{5 4}$ & $\mathbf{1 9 , 4 9 \%}$ & $\mathbf{2 7 7 / 1 0 0 \%}$ \\
\hline
\end{tabular}
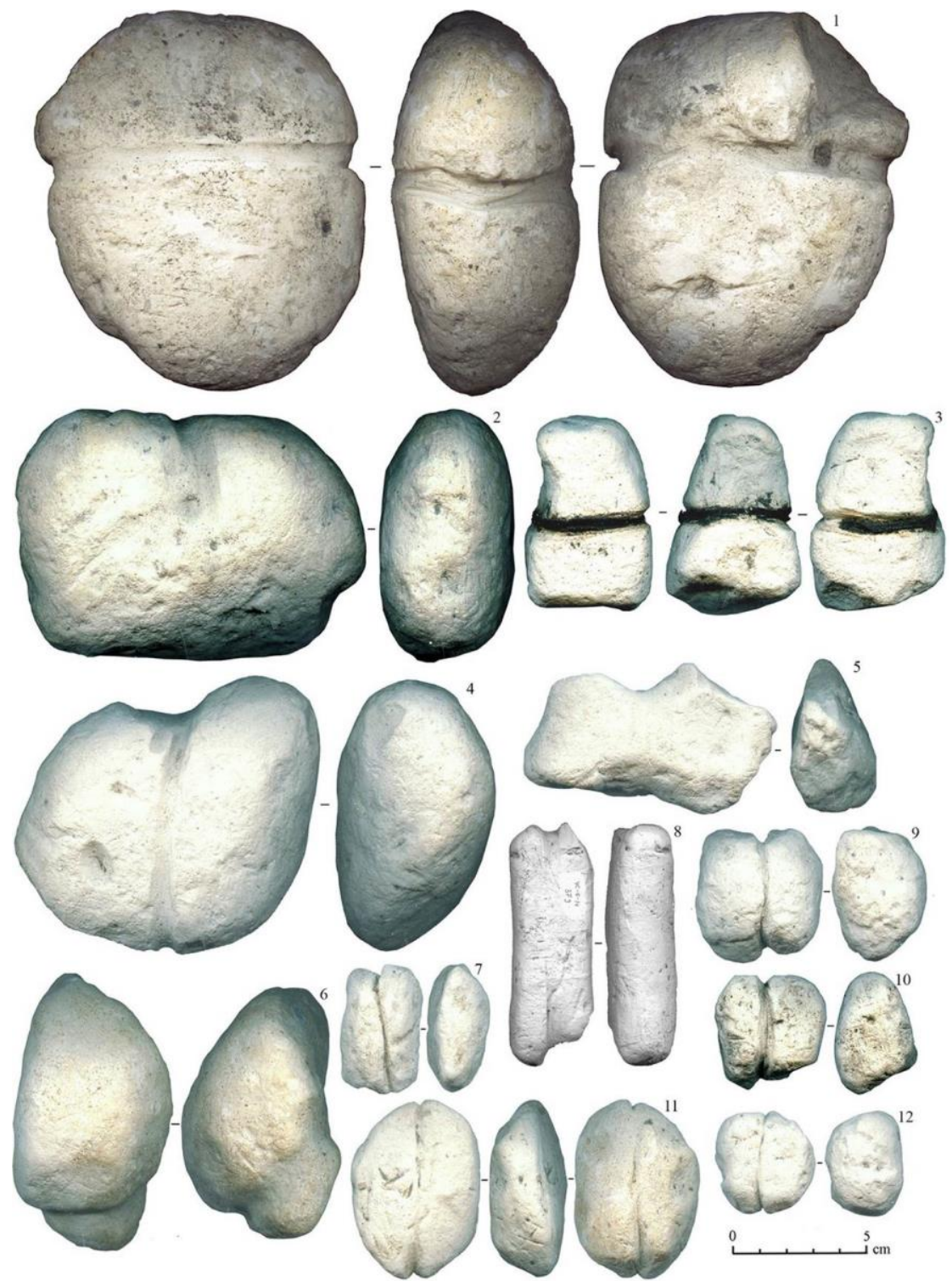

Рисунок 5 - Стоянка Черкасская-5. Изделия из мела 
Керамика 4 группы насчитывает всего 5 фрагментов стенок сосудов, в тесте примесь органики и раковины, орнамент - длинная «пунктирная» гребенка (рис. 10: 18), оттиски шнура в сочетании с зубчатым штампом (рис. 10: 7). Находит аналогии в нижнедонской культуре мариупольской КИО и в энеолитической среднестоговской (дереивской) культуре.

По мнению И.Н. Васильевой, керамика первой группы со стоянки Черкасская-5 изготовлена из тощих и жирных илистых глин (выборка состоит из 21 образца) с искусственной примесью раковины. Такая технологическая особенность характерна для керамики орловской неолитической культуры Нижнего Поволжья, начиная с третьего (нижнего) слоя стоянки Варфоломеевка [5, с. 374]. На наш взгляд, керамику с Варфоломеевки и Черкасской 5 объединяет: баночная форма сосудов и наличие посуды ладьевидной формы, накольчато-прочерченная техника орнаментации при отсутствии гребенчатого (зубча- того) штампа, украшение среза венчика, отсутствие ямочно-жемчужных поясков (несколько сосудов с «жемчужинами» появляются в слое 2А Варфоломеевской стоянки). На одном образце с Черкасской 5 имеется наплыв - утолщение изнутри по венчику (рис. 7: 2), что характерно для керамики Варфоломеевки, начиная со слоя 2Б [6, рис. 30-33]. Из отличий следует отметить округлые донца, отсутствие орнаментации внутренней стороны венчиков, меньшую распространенность геометрических мотивов и линейно-прочерченной орнаментации на Черкасской $\mathrm{V}$ стоянке. Сравнение каменной и костяной индустрии данных двух памятников не столь актуально и не дает близких аналогий, т.к. необходимо учитывать разницу в исследованных площадях, присутствие керамики других групп на Черкасской-5 стоянке, а также особенности функционирования исследованной нами части памятника [2, с. 73-74].

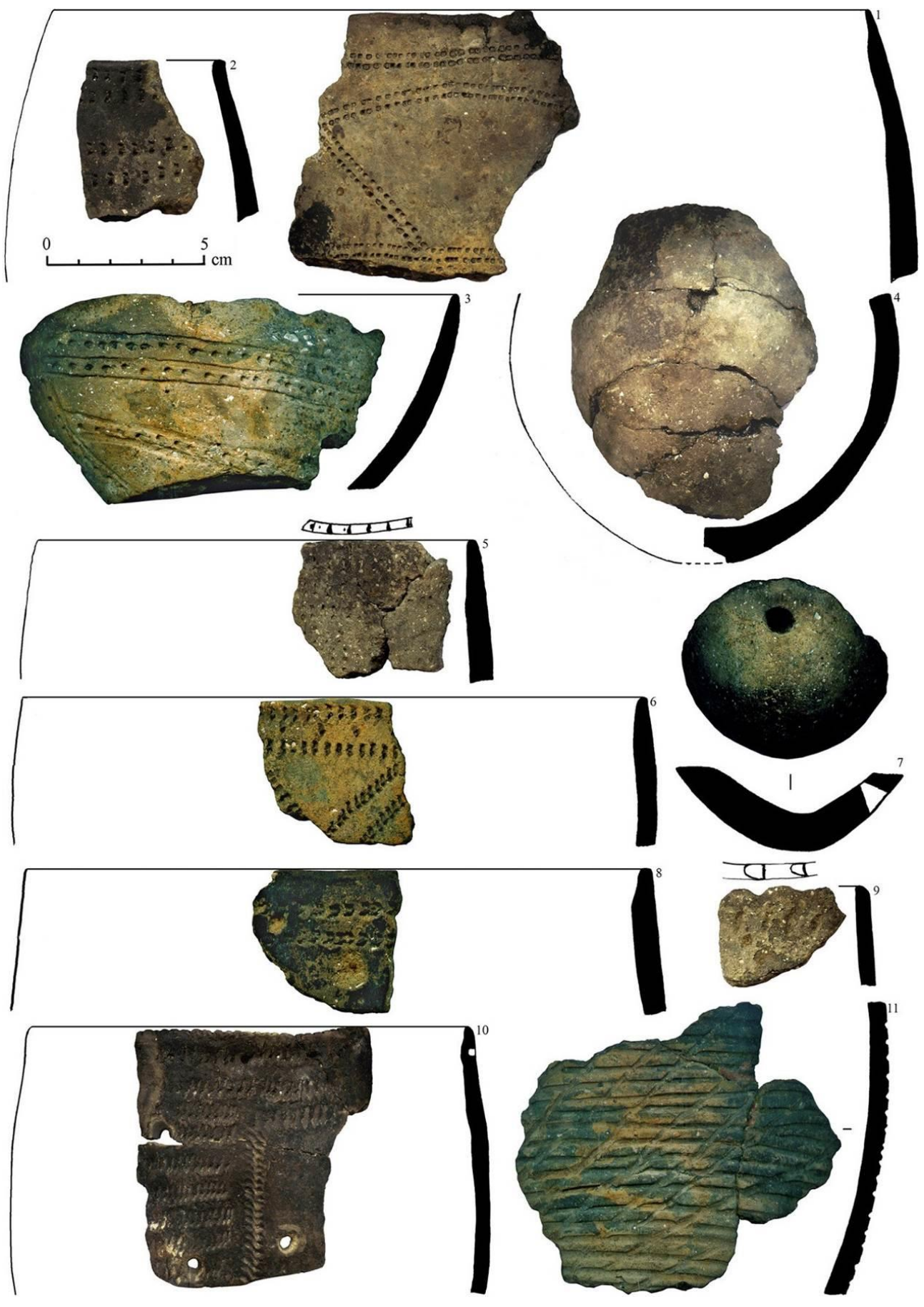

Рисунок 6 - Стоянка Черкасская-5. Керамика первой группы 
Особое внимание в коллекции памятника привлекает к себе керамика первой группы. Имеющиеся C14 даты, технико-технологические и типологические особенности позволяют относить ее к раннему неолиту. Для территории Среднего и Верхнего Подонья подобная керамика встречена впервые столь массово на стоянке Черкасская-5. Первоначально такая керамика была нами выявлена среди материалов из зачистки и сборов со стоянки Черкасская-3 в 2011 г., отнесена к энеолиту (по наличию раковины в тесте и отсутствию аналогий в местном неолите), условно названа «новым типом» с оговоркой о ее возможном будущем обретении самостоятельного культурного статуса [4, с. 153; рис. 3].

Определенные параллели в кремневой индустрии, в целом, мы найдем со многими культурами раннего неолита степи-лесостепи, в том числе и с материалами нижних слоев стоянки Варфоломеевка (нуклеусы небольших размеров, плоские и уплощенные, для снятия пластинчатых заготовок; геометрические микролиты и пластины-вкладыши; отсутствие трапеций со струганной спинкой; наличие резцов; присутствие скошенного острия и пластины с притупленным ретушью краем).

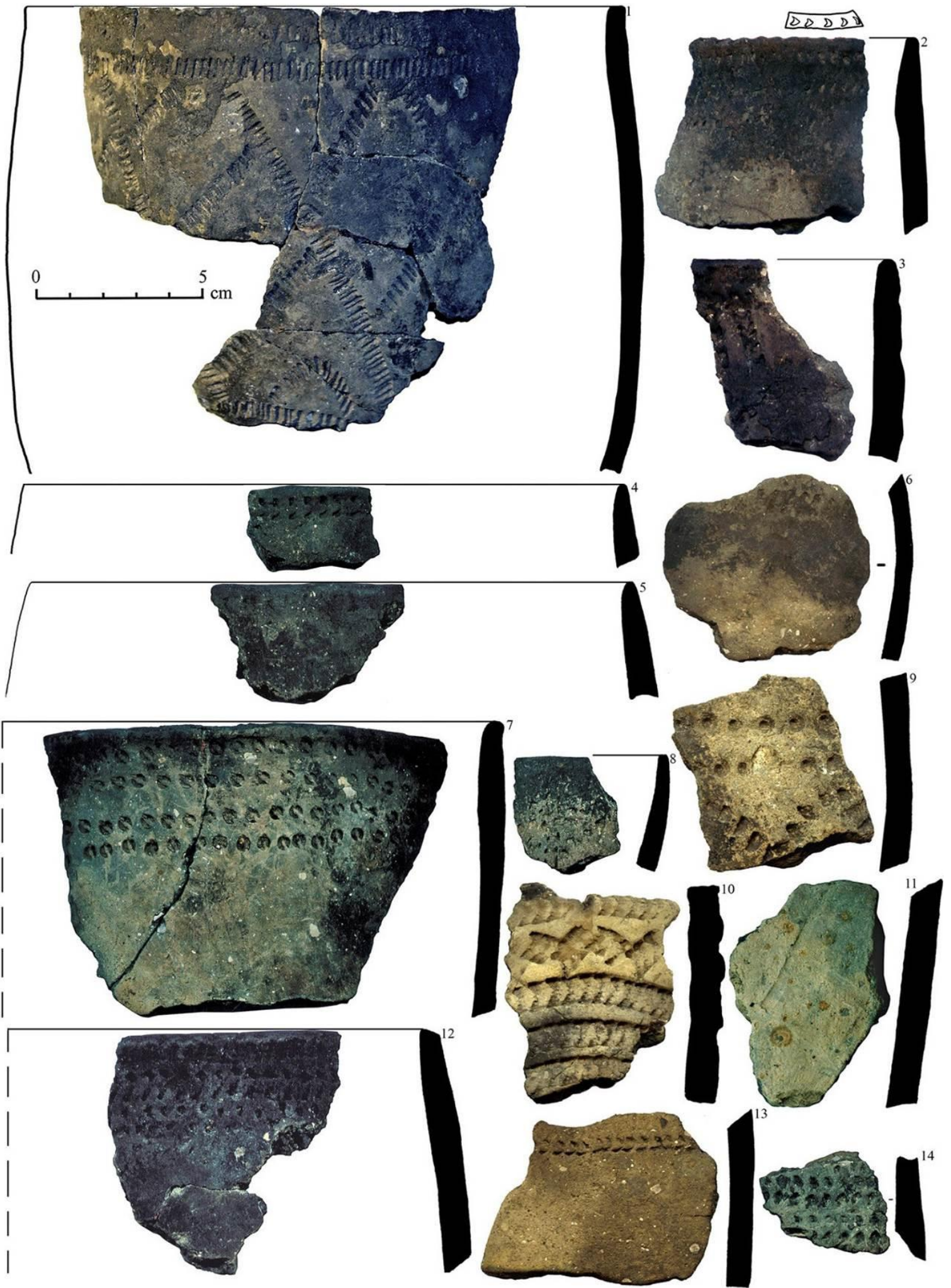

Рисунок 7 - Стоянка Черкасская-5. Керамика первой группы 
Интересно, что по большому количеству грузил, схожести в типологии рубящих орудий для деревообработки из мягких пород камня и костяных наконечников комплексы стоянки Черкасская 5 выглядят близкими к материалам поселения Раздорское II на Нижнем Дону [7, рис. 51-52; 8, рис. 9, 10, 13]. Безусловно, данное сходство можно объяснить большой ролью рыболовства в хозяйстве данных групп населения.

Таким образом, материал стоянки Черкасская-5 на данный момент выглядит достаточно архаичным на фоне неолитических культур степи-лесостепи Доно-Волжского междуречья, тяготея своими основными показателями к степной традиции раннего неолита (ракушечная примесь в тесте, заглаживание поверхностей посуды, накольчато-прочерченная орнаментация, отсутствие ямочно-жемчужных поясков в первой группе керамики, пластичная кремневая индустрия при игнорировании кварцитового сырья).

Имеющиеся C-14 даты, сделанные по керамике и нагару с керамики первой группы, делятся на две хронологические группы. Это дата по керамике $7176 \pm 100$ BP, SPb-2253 (2б 6249-5839 CalBC, см. рис. 7: 1) [9, с. 368] и дата по нагару $7115 \pm 130$ ВР, SPb-1465 (2б 6236-5730 CalBC, см. рис. 7: 2) [10, c. 253], и две более поздние даты по нагару: $6827 \pm 110$ BP, SPb-1463 (2б 5978-5550 CalBC, cм.

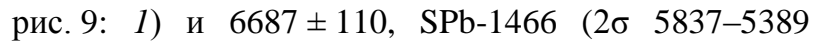
CalBC, см. рис. 7: 3) [10, с. 252].
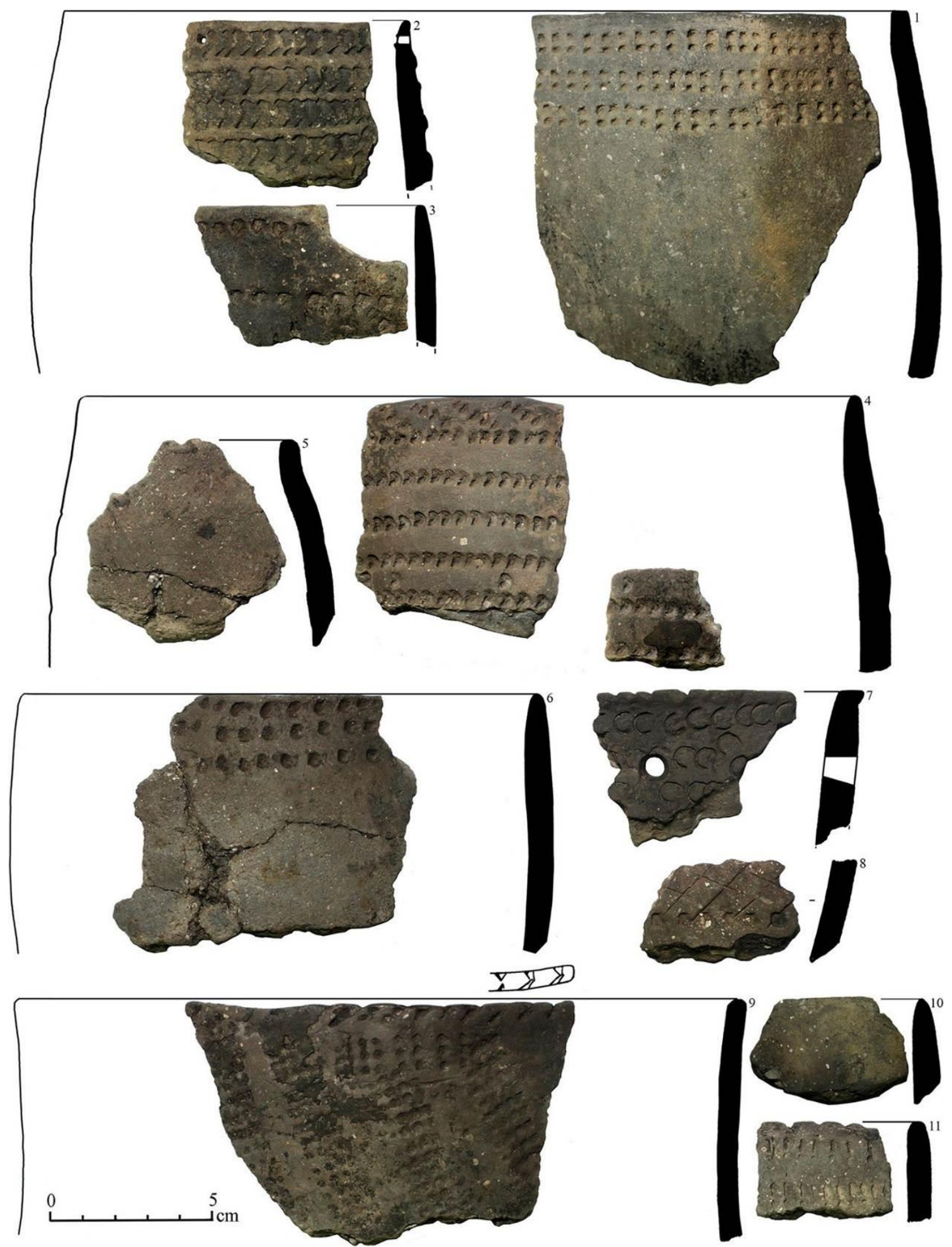

Рисунок 8 - Стоянка Черкасская-5. Керамика первой группы. Подъемный материал 
Скоробогатов А.М.

Из сапропелевого слоя зачистки № 2 был продатирован деревянный кол, впущенный из культурного слоя. Дата $5100 \pm 50$ PВ (Ki-18768) (2б 3990-3775 $\mathrm{CalBC}$. В этой зачистке отсутствовала керамика первого типа и изделия из мела. Если дата валидна, то ее можно соотнести с неолитической керамикой
2-3 групп и маркировать финал функционирования площади стоянки. Энеолитическая керамика сильно замыта, малочисленна, и не исключено, что попала в культурный слой со стоянки Черкасская-3, раскоп которой находится в 70 м на С3 от раскопа публикуемого памятника.
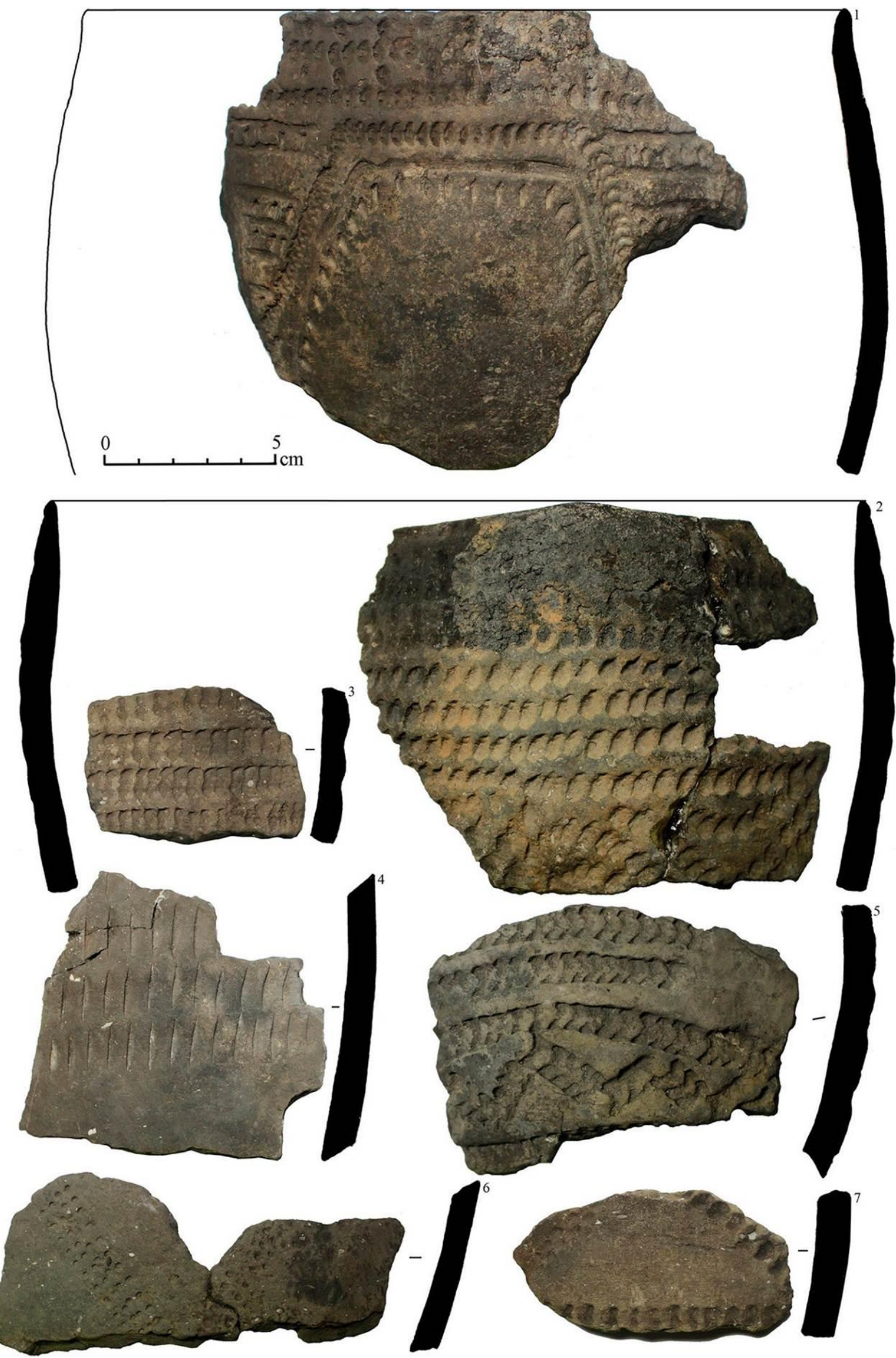

Рисунок 9 - Стоянка Черкасская-5. Керамика первой группы. Подъемный материал 


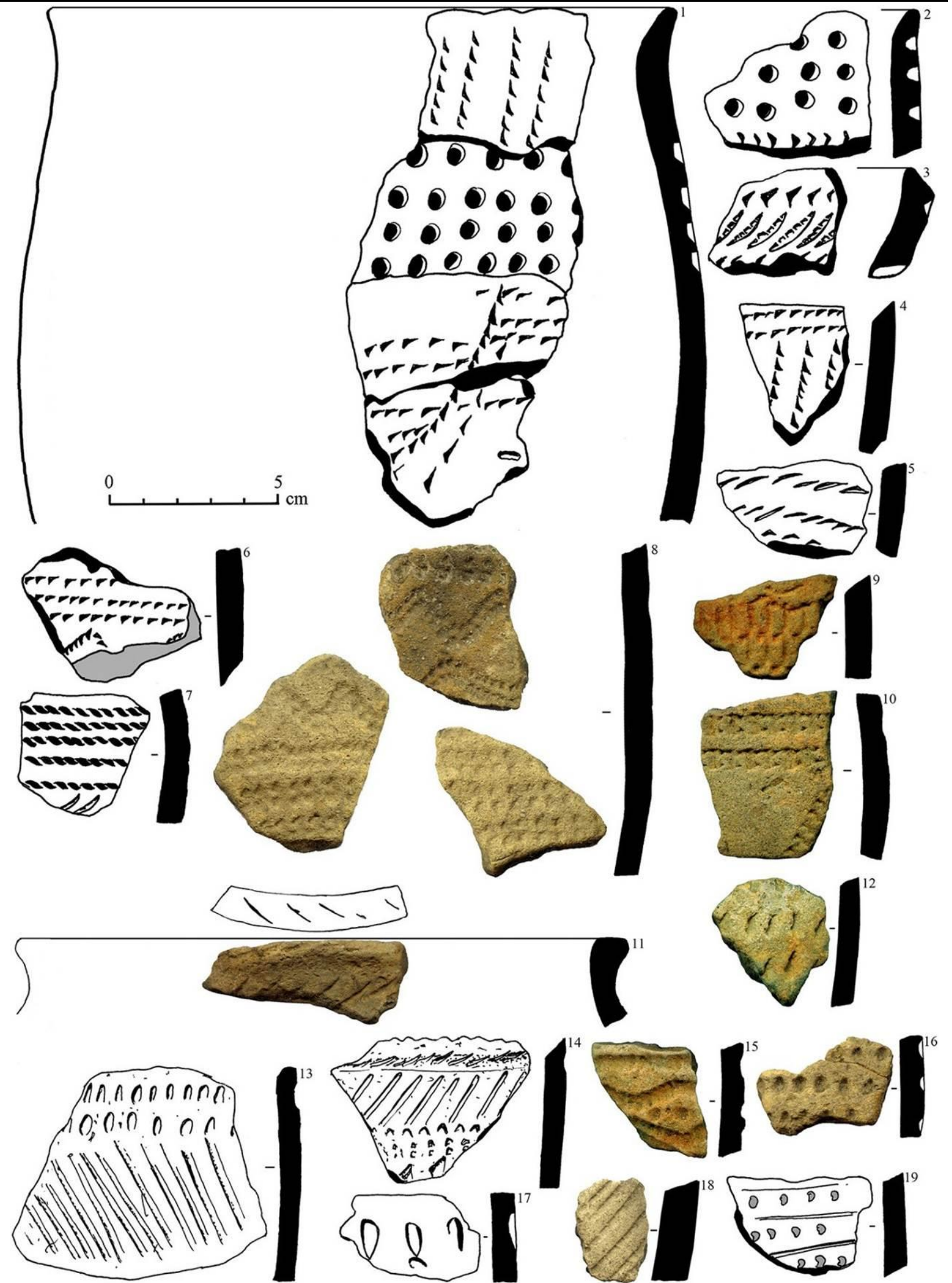

Рисунок 10 - Стоянка Черкасская-5. Керамика второй (1-6, 8-10, 12, 17), третьей $(11,13-16,19)$ и четвертой $(7,18)$ групп

Таким образом, значительная часть материалов стоянки Черкасская-5 показывает ее принадлежность к раннему неолиту, не имеющих прямых аналогий в керамических комплексах среднедонской [11] и карамышевской [12; 13] культур лесостепной части Среднего и Верхнего Подонья. Несмотря на относительную малочисленность имеющихся новых источ- ников, уже сейчас очевидна их значимость в освещении актуальных вопросов процесса неолитизации региона Донской лесостепи. На наш взгляд, именно керамические материалы первой группы стоянки Черкасская-5 сейчас претендуют на важную роль в сложении орнаментальной традиции в керамике среднедонской неолитической культуры. 
Список литературы:

1. Скоробогатов А.М. Отчет о раскопках стоянки Черкасская-5 в Павловском районе Воронежской области в 2015 г. // Архив ИА РАН.

2. Скоробогатов А.М., Яниш Е.Ю., Александровский А.Л. Неолитическая стоянка Черкасская-5 на Среднем Дону. Соотношение охоты и рыболовства по фаунистическим и археологическим данным // Стратегии жизнеобеспечения в каменном веке, прямые и косвенные свидетельства рыболовства и собирательства: мат-лы междунар. конф., посв. 50-летию В.М. Лозовского / под ред. О.В. Лозовской, А.А. Выборнова и Е.В. Долбуновой. СПб.: ИИМК РАН, 2018. С. 72-75.

3. Кузьмина И.Е., Каспаров А.К. Остатки животных из неолитических стоянок Копанище и Черкасская в Воронежской области // Плейстоценовые млекопитающие Северной Евразии. Тр. Зоол. ин-та АН СССР. Т. 168. Л.: Ленуприздат, 1987. С. 87-99.

4. Скоробогатов А.М. Материалы стратифицированной энеолитической стоянки Черкасская-3 на Среднем Дону // Проблемы изучения памятников археологии Восточной Украины. Луганск, 2012. Вып. 3. С. 152-165.

5. Васильева И.Н. К вопросу о гончарных традициях неолитического населения Подонья // Известия СНЦ РАН. 2017. Т. 19, № 3 (2). С. 370-379.

6. Юдин А.И. Варфоломеевская стоянка и неолит степного Поволжья. Саратов: Изд-во Сарат. ун-та, 2004. $200 \mathrm{c}$.
7. Цыбрий В.В. Неолит Нижнего Дона и СевероВосточного Приазовья. Ростов-на-Дону: Издательство СКНЦ ВШ ЮФУ, 2008. 199 с.

8. Цыбрий А.В., Цыбрий В.В., Горлевик А.Ф. «Затянувшаяся путина»: Неолитическое рыболовство и собирательство на Нижнем Дону (по материалам исследований поселения Раздорская II) // Stratum Plus. 2016. № 2. C. 133-174.

9. Выборнов А.А., Кулькова М.А., Ойнонен М., Посснерт Г. Новые радиоуглеродные даты неолитических памятников Подонья // Известия СНЦ РАН. 2017. T. 19, № 3 (2). C. 366-369.

10. Скоробогатов А.М., Смольянинов Р.В., Сурков А.В., Ойнонен М., Посснерт Г. Хронология неолитических памятников лесостепного Подонья // Радиоуглеродная хронология эпохи неолита Восточной Европы VII-III тысячелетия до н.э. / сост. Г.И. Зайцева, О.В. Лозовская, А.А. Выборнов, А.Н. Мазуркевич. Смоленск: Свиток, 2016. С. 244-260.

11. Синюк А.Т. Население бассейна Дона в эпоху неолита. Воронеж: Издательство Воронежского университета, 1986. $180 \mathrm{c}$.

12. Смольянинов Р.В. Ранний неолит Верхнего Дона (по данным керамических комплексов): автореф. дис. ... канд. ист. наук. СПб., 2009. 30 с.

13. Сурков А.В. Стоянка Ивница на р. Воронеж: итоги исследования 2010-2012 гг. // Археологические памятники Восточной Европы. Вып. 15. Воронеж: ВГПУ, 2013. С. 167-186.

\section{CHERKASSKAYA-5 SITE AND ITS PLACE IN THE EARLY NEOLITHIC ON THE MIDDLE DON RIVER}

\section{(C) 2018}

Skorobogatov Andrey Mikhailovich, candidate of historical sciences, head of Archeological Department LLC «Terra» (Voronezh, Russian Federation)

\footnotetext{
Abstract. The paper introduces materials of Cherkasskaya-5 site, located on the Middle Don River in the Pavlovsky district of the Voronezh Region. Under the two-meter thickness of the lake-alluvial layers, more than a thousand pieces of finds have been ceramics, stone, bone products and osteology. While analyzing the materials of the monument a ceramic and flint complex of the Early Neolithic appearance have been distinguished (7-6 thousand BC). The received radiocarbon dates, the data of technical and technological analysis and the features of ornamentation, ceramics, the typology of stone and bone inventory, help to find one of the possible ways of Neolithization of the Middle Don, in which the leading role belongs to the steppe component. Paleozoological analysis showed that the osteological collection is dominated by the bones of birds (64,4\% of all bones), there are mammals $(21,8 \%)$, fish $(9,7 \%)$, turtle marsh $(4,1 \%)$. Among domestic mammals domestic species (dog, horse, pig, sheep) are identified. However, the presence of late Neolithic and Eneolithic (srednedonskaya, dnepro-donetskaya, nizhnedonskaya, and srednestogovskaya cultures) in the ceramics layer leaves open the question of the domestic animal species belonging to the early Neolithic. The material of the site makes it possible to characterize this place as a series of seasonal short-term specialized sites intended for conducting network fishing, hunting for waterfowl, catching turtles and collecting shellfish as well as for processing the products of fishing and hunting in the Neolithic age.

Keywords: Middle Don; Bityug river; Voronezh Region; forest-steppe; excavations; site; stratigraphy; ceramics; stone and bone products; radiocarbon dates; early Neolithic; steppe tradition; pencil-drawn ornamentation; orlovskaya culture; hunting; fishing; sinker; gathering; domestic animals.
}

\section{КАМЕННАЯ ИНДУСТРИЯ РАННЕГО НЕОЛИТА ВЕРХНЕГО ДОНА}

Смольянинов Роман Викторович, кандидат исторических наук, заведующий кабинетом археологии и этнологии

Юркина Елизавета Сергеевна, старший лаборант кафедры отечественной и всеобщей истории Липеикий государственный педагогический университет имени П.П. Семенова-Тян-Шанского (2. Липеик, Российская Федерация)

Аннотащия. Практически все пойменные поселения бассейна р. Дон и его притоков являются многослойными. До последнего времени говорить о каменной индустрии раннего неолита Верхнего Дона не представ- 